\title{
Expressão dos marcadores tumorais CD-34 e CASPASE-3 no carcinoma epidermóide de esôfago
}

\section{CD-34 and CASPASE-3 biomarkers expression in esophageal epidermoid carcinoma}

Valério Alves Ferreira ; Nicolau Gregori Czeczko²; Jurandir Marcondes Ribas-Filho²; Osvaldo Malafaia²; Carmen Austrália Paredes Marcondes Ribas ${ }^{2}$; Claudia Stein Gomes ${ }^{1}$; Regina Maria da Cunha ${ }^{1}$; Ronaldo M. Cuenca 3

\author{
RES U M O
}

\begin{abstract}
Objetivo: Analisar citofotometricamente a expressão do marcador de densidade microvascular CD-34 e de apoptose caspase-3 no carcinoma epidermóide de esôfago, e correlacionar os marcadores entre si. Métodos: Análise imunoistoquímica de 29 peças cirúrgicas de carcinomas epidermóides de esôfago, baseada nos índices de marcagem dos anticorpos CD-34 e caspase-3, utilizandose sistema de citofotometria computadorizada. Comparou-se a expressão quantitativa destes marcadores, a relação entre eles, a relação com a idade dos pacientes, tamanho das lesões e classificação TNM. Resultados: O valor da mediana do índice de marcagem do CD-34 foi de $72,6 \%$ e o da caspase-3 de 96,5\%. Não se obteve significância estatística na correlação destes marcadores com o tamanho tumoral ou com a idade dos pacientes. Houve discreta tendência à correlação positiva entre o CD-34 e a classificação TNM. O marcador caspase-3, apesar de apresentar maior índice de marcagem que o CD-34 nestes tumores, não revelou nenhuma correlação com as variáveis estudadas. A correlação entre o CD-34 e a caspase-3 apresentou tênue tendência positiva. Conclusão: Ambos os marcadores têm boa expressão no carcinoma epidermóide de esôfago, onde o CD-34 tem menor expressividade que a caspase-3 e os mesmos não apresentam correlação entre si.
\end{abstract}

Descritores: Antigens. CD34. Citofotometria. Carcinoma de células escamosas. Neoplasias esofágicas.

\section{INTRODUÇÃO}

A pesar da melhor compreensão e dos constantes avanços da oncologia tanto no diagnóstico quanto na terapêutica de diversos tumores, existem algumas neoplasias que persistem com sua história natural quase inalterada, com evolução sombria, face ao diagnóstico tardio e aos dados insuficientes de estadiamento para melhor planejamento terapêutico.

O carcinoma epidermóide de esôfago tem prognóstico particularmente ruim, com rápida progressão clínica, alta freqüência de linfonodos acometidos, recorrência pós-ressecção cirúrgica elevada e taxa de mortalidade de cerca de $90 \%$ em cinco anos. Neste tumor, assim como nos demais, o estadiamento TNM, o grau de diferenciação, a ploidia e as metástases linfonodais são fatores prognósticos importantes ${ }^{1}$. A evolução técnico-científica das últimas décadas vem permitindo cada vez mais a compreensão da tumorigênese, sua progressão e metastatização, com o desenvolvimento de conceitos como angiogênese tumoral e apoptose celular. Neste sentido foram desenvolvidos marcadores imunoistoquímicos de angiogenêse e de apoptose para melhor investigação destes fenômenos nos processos tumorais².
Weidner et al. ${ }^{3}$, descreveram pela primeira vez correlação prognóstica de um câncer (mamário) e a expressão do marcador imunoistoquímico para angiogênese, o anticorpo monoclonal anti-Fator VIII. No carcinoma epidermóide de esôfago esta correlação também foi bem documentada, alguns anos depois ${ }^{4}$, porém, com o anticorpo anti-CD-34 que marca células precursoras de endotélio. No ano seguinte ${ }^{5}$, foi demonstrado que alguns casos de carcinoma de esôfago, com linfonodos negativos à anatomopatologia convencional, tinham alta expressividade do CD-34 com alto valor preditivo positivo para metástase e fator prognóstico independente.

O fenômeno de apoptose foi descrito por Kerr et al. ${ }^{6}$ como a morte programada da célula que, em resposta a um estímulo interno ou externo, desencadeia uma série de eventos intracelulares que culminam no seu auto-extermínio fisiológico, sem desenvolvimento de necrose ou inflamação. A apoptose celular, quando reduzida, pode predispor ao aparecimento de neoplasias, pois tem debilitada a sua função de eliminar as células com material genético defeituoso ${ }^{7}$. Esta apoptose deficiente nos tumores pode ser estudada mediante técnicas imunoistoquímicas, entre elas a que utiliza o anticorpo anti-caspase-3.

Trabalho realizado no Programa de Pós-Graduação em Princípios da Cirurgia - Hospital Universitário Evangélico de Curitiba / Faculdade Evangélica do Paraná - Curitiba - PR - Brasil.

1. Mestre do Programa de Pós-graduação em Princípios da Cirurgia pela Faculdade Evangélica do Paraná - Curitiba - PR, BR; 2. Doutor, Professor Permanente do Programa de Pós-graduação em Princípios da Cirurgia da Faculdade Evangélica do Paraná - Curitiba - PR, BR; 3. Doutor em Clínica Cirúrgica pela Universidade Federal do Paraná - Curitiba - PR, BR. 
A apoptose de células endoteliais precede a das células tumorais e, portanto, drogas atuantes na apoptose endotelial poderiam potencializar a ação quimioterápica na massa tumoral e reduzir a sua quimioresistência. $\mathrm{O}$ endotélio tem sensibilidade mais duradoura às drogas do que as células tumorais, uma vez que ele não sofre mutações ${ }^{8}$.

As leituras da caspase-3 e do CD-34 podem ser realizadas de diversas formas, desde métodos convencionais de densidade microvascular até os computadorizados de citometria de fluxo e de imagem ${ }^{9}$. As divergências sobre o melhor método de quantificação da expressividade dos diversos marcadores tumorais, o possível viés metodológico e a necessidade de padronização dos resultados motivou à utilização de um sistema automático de leitura citofotométrica chamado SAMBA - Système d'Analyse Microscopique à Balayage Automatique.

Baseado na conhecida correlação entre angiogênese e apoptose - bastante explorada na oncoterapia com drogas antiangiogênicas -, objetivou-se avaliar no carcinoma epidermóide de esôfago a expressividade e correlação entre os marcadores tumorais CD-34 e caspase-3, procurando analisar citofotometricamente a expressão do marcador de densidade microvascular, CD-34 e de apoptose caspase-3, e verificar a correlação destes marcadores entre si, a relação com a idade dos pacientes, tamanho das lesões e classificação TNM.

\section{MÉTODOS}

Este estudo foi realizado no Instituto de Pesquisas Médicas (IPEM) do Programa de Pós-Graduação em Princípios da Cirurgia do Hospital Universitário Evangélico de Curitiba / Faculdade Evangélica do Paraná e no CITOLAB -Laboratório de Citologia e Histopatologia Ltda, da cidade de Curitiba e foi aprovado pelo Comitê de Ética em Pesquisa da Sociedade Evangélica Beneficente.

O material foi constituído por 29 blocos de parafina de carcinoma epidermóide de esôfago de pacientes submetidos à esofagectomias com intuito curativo em hospitais de Brasília (DF) e Teresina (PI) no Brasil.

Nenhum tinha metástase à distância reconhecida pré-operatoriamente e 17(58\%) apresentavam acometimento linfonodal (técnica de amostragem por conveniência). A maioria $(n=25)$ dos pacientes era do sexo masculino e a mediana de idade foi de 58,5 anos com idade mínima de 40 anos e máxima de 70 .

Dividiu-se em grupos com mais de 60 e menos de 60 anos. A maioria dos tumores tinham mais que $3 \mathrm{~cm}$ de extensão ( $n=68 \%$ ) e grau histológico moderadamente diferenciado $(n=71 \%)$. A maioria dos pacientes $(n=68 \%)$ tinha estadiamento T3 (T3N1MO e T3NOMO) e o restante T2 (T2N1M0 e T2NOM0), segundo a classificação TNM.

Os blocos de parafina contendo fragmentos de tecido tumoral foram numerados de 1 a 29 e apresenta- vam-se em bom estado de conservação, sem defeito de parafinização, vácuo ou fungos intrabloco.

Cada bloco recebido foi submetido à microtomia obtendo-se cortes histológicos de 5 micra de espessura, os quais foram distendidos em lâminas e encaminhados à coloração de HE para a confirmação diagnóstica. Elas foram analisadas segundo os critérios histológicos para o diagnóstico de carcinoma epidermóide de esôfago e seu grau de diferenciação. Diagnóstico discordante de carcinoma epidermóide de esôfago não foi encontrado em nenhuma amostra.

As demais lâminas até então não coradas, foram submetidas à técnica imunoistoquímica padrão para os marcadores. No entanto na coloração para a caspase-3 a amostra definitiva ficou em 28 casos devido a problemas técnicos.

A citofotometria foi efetuada no sistema SAMBA 4000 fabricado pela Alcatel (Grenoble/França). O hardware foi composto por microscópio, vídeo-câmera, microcomputador e impressora.

O software utilizado foi o Imunno® versão 4.0, capaz de capturar a densidade óptica, em suas diferentes escalas de cinza, da coloração imunoistoquímica dos tecidos, quantificando assim a expressividade de determinado marcador de maneira automática. Este método evita eventuais erros de mensuração causados pela subjetividade e baixa sensibilidade da análise visual. O olho humano é capaz de detectar até 32 escalas de cinza, ao passo que o computador detecta 256 tons ou mais, conforme sua capacidade de processamento.

O fluxo luminoso, oriundo da lâmpada de xenônio, é trabalhado por um potenciômetro capaz de controlar com precisão a quantidade de luz que atravessa a lâmina. Este feixe atravessa o condensador, a lâmina histológica e a objetiva em uso. Neste ponto ele é separado em duas partes: uma via para observação visual através da ocular e outra direcionada para captação da imagem pela câmera de vídeo a qual é enviada ao computador.

A captura das imagens padroniza as cores verde, azul e vermelha, calibrando o sistema. O computador faz as seguintes funções: importar as imagens do microscópico e da câmara de vídeo, executar o software Immuno ${ }^{\circledR}$ do sistema SAMBA e transferir os dados para impressão.

Ao iniciar a utilização o software realiza-se a calibração do sistema SAMBA e padronizar o protocolo.

As imagens analógicas iniciais são captadas pela câmera e digitalizadas. A digitalização tem por finalidade transformar as imagens coradas pelo marcador em matriz numérica que permite calcular parâmetros matemáticos que possibilitem a leitura.

As imagens são digitalizadas em pixels que é a unidade de cada ponto-imagem. A quantificação da luz absorvida é expressa em escala de cinza que vai do 0 (preto, onde não há tecido) ao 255 (branco, onde a concentração do tecido é a maior) gerando uma matriz de tons de cinza que é transformada em matriz binária. 
A lâmina de imunoistoquímica é inicialmente avaliada ao microscópico óptico em campo de 100x com rastreamento dos campos visuais em barra grega ${ }^{10}$, onde se escolhem três áreas quentes, ou seja, com maior densidade do marcador imunoistoquímico. Em seguida estas áreas são reavaliadas em campo de 400x em área correspondente a 0,754 $\mathrm{mm}^{2}$ que é capturada pela vídeo-câmera e posteriormente analizadas pelo computador.

O software analisa uma variável da coloração imunoistoquímica chamada de índice de marcagem que denota a porcentagem de área tecidual marcada pela prova imunoistoquímica. Este índice tem relação direta com a sensibilidade do marcador, a reatividade da amostra e a adequada realização das etapas do método imunoistoquímico.

A análise descritiva ou univariada foi realizada mediante o cálculo das freqüências e das porcentagens quando as variáveis eram qualitativas; e medianas para as variáveis quantitativas. Na avaliação de independência de duas variáveis foram utilizados testes não paramétricos. O teste de Mann - Whitney foi utilizado quando associouse variável qualitativa dicotômica com variável quantitativa e a correlação de Spearman quando associado à duas variáveis quantitativas. O teste de Wilcoxon foi realizado quando comparou-se duas variáveis quantitativas relacionadas. Na avaliação de hipótese, a rejeição da hipótese nula (Ho) foi considerada quando o valor de $P$ foi menor que 0,05 , o que define que as diferenças foram consideradas significativas. Para esses cálculos estatísticos foi empregado o software SPSS $®$ versão 13 (SPSS Inc., Chicago, Illinois, USA).

\section{RESULTADOS}

Observou-se a expressão do CD-34 ao longo da membrana citoplasmática e da caspase-3 no citoplasma.

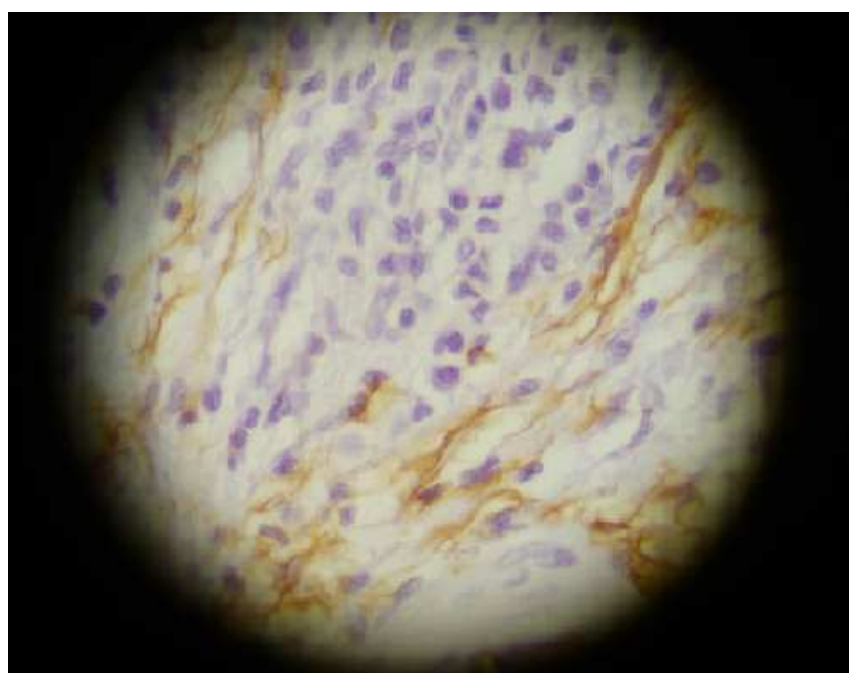

Figura 1 - Fotomicrografia de lâmina de carcinoma epidermóide de esôfago imunomarcada com CD-34 (aumento de 400x).
Nas regiões marcadas ocorreu coloração castanha e o fundo não marcado ficou de tonalidade azulada devido à coloração HE. Na técnica de coloração imunoistoquímica, a marcação das lâminas pelo anticorpo anti-CD-34 teve homogeneidade satisfatória. A marcação pela caspase-3 foi satisfatória, exceto em um paciente (Figuras 1 e 2).

\section{Análise do CD-34}

Na avaliação univariada, os valores do índice de marcagem apresentaram ampla variação. O valor mais baixo foi $46,8 \%$, o mais alto $98,7 \%$ e a mediana $72,6 \%$ (Figura 3).

Na avaliação bivariada, a variável sexo não pôde ser considerada estatisticamente devido ao número muito reduzido de indivíduos do sexo feminino $(n=4)$. O mesmo ocorreu em relação ao grau de diferenciação dos tumores, em que o baixo número de tumores bem diferenciados $(n=6)$ e pouco diferenciados $(n=3)$ inviabilizaram a análise estatística.

A idade dos pacientes não apresentou significância estatística sobre o índice de marcagem ( $p=0.95$ ).

Nas lesões maiores de $3 \mathrm{~cm}$ observou-se valor maior do índice de marcagem (mediana $=72,3 \%$ ) que nas lesões menores que $3 \mathrm{~cm}$ (mediana $=68,2$ ), porém sem significância $(p=0.96)$.

Os pacientes com estágio T3 (T3N1M0 e T3NOM0) apresentaram tendência a maiores valores do índice de marcagem (mediana $=73,1 \%$ ) que aqueles com estágio T2 (T2NOM0, T2N1M0), cuja mediana foi de 64, $1 \%$ com $P$ de 0,11 , o mesmo ocorrendo em relação ao acometimento linfonodal com $p=0,12$ (Tabela 1).

\section{Análise da caspase-3}

Na avaliação univariada, os valores do índice de marcagem da caspase-3 apresentaram também ampla variação onde o valor mais baixo foi $47,1 \%$, o mais alto $99,4 \%$ e a mediana $96,5 \%$.

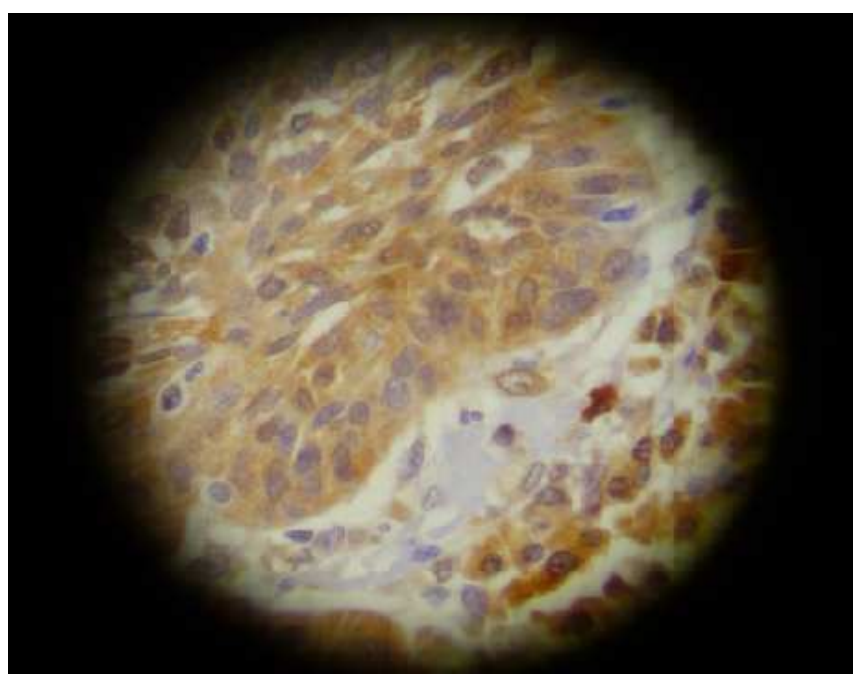

Figura 2 - $\quad$ Fotomicrografia de lâmina de carcinoma epidermóide de esôfago imunomarcada pela caspase-3 mostrando forte impregnação citoplasmática (aumento de 400x). 


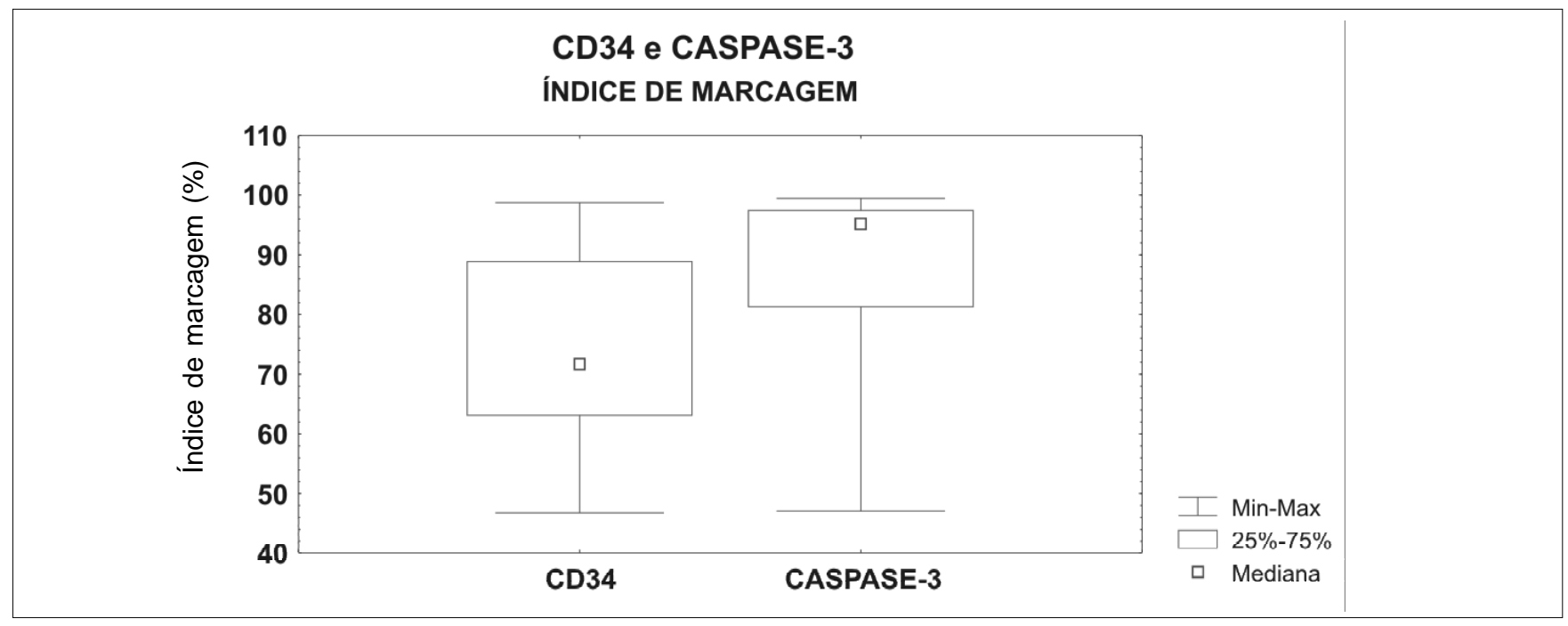

Figura 3 - Boxplot comparativo entre a distribuição do índice de marcagem.

Na avaliação bivariada, a variável sexo não pôde ser avaliada estatisticamente devido ao número muito reduzido de indivíduos do sexo feminino na amostra $(n=4)$. O mesmo ocorreu em relação ao grau de diferenciação dos tumores, em que o baixo número dos bem diferenciados $(n=6)$ e pouco diferenciados $(n=3)$ inviabilizaram a análise estatística.

A idade dos pacientes não apresentou significância estatística sobre o índice de marcagem $(p=0,19)$.

Nas lesões maiores de $3 \mathrm{~cm}$ observou-se valor maior do índice de marcagem (mediana $=95,4 \%$ ) que nas lesões menores que $3 \mathrm{~cm}$ (mediana $=88,6 \%$ ), porém sem significância $(p=0,56)$.

O estágio T3 (T3N0M0 e T3N1M0) não apresentou diferença na expressão da caspase-3 (mediana = 95,2\%) em relação aqueles pacientes com estágio T2 (T2NOM0 e T2N1M0) cuja mediana foi de $83,3 \%(p=0,21)$ e o mesmo ocorrendo em relação ao acometimento linfonodal com $p=0,57$ (Tabela 2).

\section{Correlação entre os marcadores}

Houve diferença significativa $(P=0.007)$ entre os índices de marcagem do CD-34 e da caspase-3, sendo a expressão da caspase-3 significativamente maior que o CD34 (Figura 3).

Quando comparados os índices de marcagem da caspase-3 com o do CD-34, não foi encontrada correlação significativa entre eles (correlação de Spearman =0,091; $p=0,65$.

\section{DISCUSSÃO}

Apesar de vasculogênese ter sido descrita no início do século passado por Sabin em 1917 com a descoberta do angioblasto, os mecanismos genético e molecular que controlam o desenvolvimento do sistema vascular permaneceu um mistério até recentemente. Somente em 1971, com
Tabela 1 - Correlação entre o índice de marcagem do CD34 versus variáveis.

\begin{tabular}{lccc}
\hline & \multicolumn{2}{c}{ Indice do CD-34 } & \\
\cline { 2 - 3 } & Casos & Mediana & Valor de $p^{*}$ \\
\hline Idade (anos) & & & \\
40 a 60 & 16 & $69,9 \%$ & 0,95 \\
61 a 70 & 13 & $68,2 \%$ & \\
Tamanho da lesão & & & \\
Maior 3 cm & 19 & $72,3 \%$ & 0,96 \\
Menor 3 cm & 9 & $68,2 \%$ & \\
Estadiamento (TNM) & & & \\
T2N0M0 e T2N1M0 & 8 & $64,1 \%$ & 0,11 \\
T3N1M0 e T3N0M0 & 21 & $73,1 \%$ & \\
Linfonodos acometidos & & & \\
Não & 13 & $66,0 \%$ & 0,12 \\
Sim & 16 & $74,0 \%$ & \\
\hline
\end{tabular}

* Valor de significância calculado pelo teste de Mann-Whitney.

Tabela 2 - Correlação entre o índice de marcagem da caspase-3 versus variáveis.

\begin{tabular}{lccc}
\hline & \multicolumn{3}{c}{ Indice da caspase -3} \\
\cline { 2 - 3 } & Casos & Mediana & Valor de $p^{*}$ \\
\hline Idade (anos) & & & \\
$\quad 40$ a 60 & 15 & $79,3 \%$ & 0,19 \\
$\quad 61$ a 70 & 13 & $88,6 \%$ & \\
Tamanho da lesão & & & \\
$\quad$ Maior 3 cm & 18 & $95,4 \%$ & 0,56 \\
$\quad$ Menor 3 cm & 9 & $88,6 \%$ & \\
Estadiamento (TNM) & & & \\
$\quad$ T2N0M0 e T2N1M0 & 7 & $83,3 \%$ & 0,21 \\
$\quad$ T3N1M0 e T3N0M0 & 21 & $95,2 \%$ & \\
Linfonodo acometido & & & \\
$\quad$ Não & 12 & $92,1 \%$ & 0,57 \\
Sim & 16 & $95,2 \%$ & \\
\hline
\end{tabular}

* Valor de significância calculado pelo Teste de Mann-Whitney. 
os estudos de angiogênese tumoral de Folkman iniciou-se um crescente entendimento sobre o crescimento dos vasos e capilares sanguíneos utilizando-se as culturas in vitro de células endoteliais e a descoberta subseqüente de proteínas que têm ação mitogênica sobre estas células endoteliais como o fator de crescimento de fibroblasto (bFGF) e o fator de crescimento do endotélio vascular (VEGF) ${ }^{12}$. Segundo Risau et al. ${ }^{11}$, a vasculogênese e a angiogênese são os dois tipos básicos de proliferação vascular. A vasculogênese se faz a partir do angioblasto ou célula precursora presente somente na fase embrionária. A angiogênese por sua vez, a partir de células endoteliais pré-existentes que se proliferam como o broto de uma árvore.

Em 1971, Folkman propôs que o crescimento tumoral requer o desenvolvimento de novos microvasos ou angiogênese. Desde então vários estudos têm mostrado que estes novos vasos são importantes não só para a nutrição tumoral, mas também para produção de fatores de crescimento tumorais e para prover uma rota para a disseminação de metástases. O crescimento tumoral e as metástases dependem da angiogênese a qual é estimulada por um fator químico produzido pelas próprias células tumorais. Na fase pré-vascular o tumor pode atingir até $3 \mathrm{~mm}$, pois é o limite máximo da difusão dos nutrientes nos tecidos sem capilares. Nesta fase o crescimento tumoral é latente, uma vez que a proliferação celular é neutralizada pela apoptose celular intratumoral. Na fase angiogênica há redução da apoptose, permitindo assim o crescimento tumoral. Nesta etapa o tumor aumenta a sua produção de fatores angiogênicos que superam a ação dos fatores inibidores de angiogênese local. A matrix intercelular e os macrófagos também são fontes de proteínas angiogênicas que podem participar deste processo ${ }^{8}$. 0 tumor neovascularizado cresce não só por efeito da perfusão, a qual é mais efetiva que a difusão na nutrição dos tecidos, mas também por efeito parácrino resultante da produção de fatores de crescimento produzidos pelas células endoteliais ${ }^{13}$ que atuam sobre as células tumorais. Katz et al. ${ }^{14}$ descobriram uma proteína transmembrana celular chamada CD-34 presente em células progenitoras de endotélio na medula óssea utilizando um anticorpo monoclonal anti-CD-34, e Asahara et al. ${ }^{15}$ encontraram células progenitoras de endotélio, CD-34 positivas, em circulação no sangue periférico de adultos contradizendo o paradigma de que a vasculogênese fosse restrita ao período embrionário.

Asahara et al. ${ }^{16}$ descreveram que o endotélio tumoral, de áreas de isquemia ou de injúria vascular produz o VEGF que é o fator responsável pela migração das células progenitoras de endotélio da medula óssea até o local de injúria, onde se concentram produzindo vasculogênese. Portanto a neo-angiogênese tumoral se faz por vasculogênese que é detectada por um marcador imunoistoquímico, o anticorpo anti-CD-34.

Já as caspases são grupos de proteínas com um radical composto por um aminoácido cisteína que confere propriedade específica entre as demais proteases, tornando-a capaz de clivar um resíduo de ácido aspártico. O nome caspase se origina, portanto, de sua função molecular: cysteine-aspartic-acid-proteases. Estas enzimas são essenciais à apoptose celular, que entre outras funções, age como um filtro eliminando as células com erros genéticos irreparáveis diminuindo o risco de desenvolvimento de tumores. A cascata de ativação das caspases se faz por estímulos extracelulares como TNF que estimulam os receptores de membrana (FAS, TRAIL e TNF-R1) que podem ativar as caspases 8 e 10 ou ativar o apoptosome (na mitocôndria), o citocromo c e a família $\mathrm{Bcl}$-2. Uma vez iniciada a cascata, o feedback positivo assegura o processo irreversível de apoptose com ativação da caspase-9 que cliva a caspase-3 que por sua vez lisa as proteínas alvo como a poli (ADP) ribose polimerase e o inibidor da caspase activated DNase (ICAD). Isto permite que a $C A D$ entre no núcleo e fragmente o DNA ${ }^{17}$. A caspase-3, que é analisada neste estudo, foi historicamente o terceiro grupo de caspase a ser descoberto, e se chamava inicialmente CPP32 pelo seu peso molecular de 32 KDa. Trata-se de uma enzima classificada como efetora, pois atua na fase final da apoptose para a qual convergem todas as vias de sinalização. No entanto, somente quando a caspase-3 se cliva em uma molécula de $20 \mathrm{KDa}$ que ela se torna funcionalmente ativa, capaz de ativar a apoptose.

O potencial uso da caspase-3 como fator prognóstico tumoral ainda não está bem estabelecido nos ensaios clínicos já realizados, embora autores ${ }^{18,19}$ encontraram correlação significativa da caspase-3 com fatores prognósticos e sobrevida.

Em diversos cânceres humanos, a densidade microvascular intratumoral têm sido apontada como fator independente de significância prognóstica e preditor de doença metastática, no entanto, a quantificação da angiogênese tumoral tem valor preditivo/prognóstico questionável devido à grande dificuldade de se controlar o possível viés durante a sua realização. Este fato motivou o Colégio Americano de Patologistas a classificar os diversos métodos de quantificação vascular como nível de evidência $\left.1\right|^{20,21}$.

A microscopia computadorizada ou citometria de imagem é especialmente útil, pois permite a combinação de informações tanto da observação histológica como molecular. Os marcadores passam a ser quantificados de maneira precisa e dinâmica contrapondo-se com as técnicas anteriores, estáticas, apenas baseadas na análise morfológica. A partir de 1980, técnicas de computação permitiram que a imagem captada fosse transformada em imagem numérica com maior velocidade, a um custo razoável, e possibilitaram o tratamento estatístico dos dados tornando-se método auxiliar nas definições de diagnóstico e planejamento terapêutico ${ }^{22}$. A citometria de imagem pode ser de grande utilidade no afastamento do caráter subjetivo da interpretação de cortes histológicos onde existe a dificuldade de se obter uma classificação. Esta técnica permite 
real ajuda quando se utilizam programas que quantificam em porcentagem áreas marcadas por técnicas imunoistoquímicas. A rapidez no processo de leitura das lâminas e a realização de métodos estatísticos de alta performance possibilitam a melhor interpretação dos resultados, os quais podem ser padronizados melhorando o controle de qualidade e reprodutibilidade.

O método SAMBA utilizado neste trabalho mantém todas as características das demais citometrias computadorizadas de imagem, exceto a leitura automatizada de toda a superfície da lâmina. As lâminas de imunoistoquímica foram analisadas inicialmente em microscópico óptico com ampliação de 100 vezes para a escolha da área de maior impregnação pelo imunomarcador. Esta fase de escolha da área da lâmina a ser lida não difere dos métodos convencionais e está sujeita a viés inter-observador. Uma vez delimitada a área específica da lâmina a ser quantificada, ela recebe ampliação microscópica de 400 vezes, sendo fotografada e digitalizada, para iniciar a fase automatizada do processo.

\section{Correlação entre CD-34 e caspase-3}

Vários trabalhos relacionam a isquemia local e a ação de quimioterápicos sobre o endotélio tumoral como importante estímulo para apoptose. Têm-se, portanto, aumentado os estudos sobre a potencialização da apoptose tumoral por meio da supressão da angiogênese tumoral, pelo seu grande potencial terapêutico ${ }^{8}$.

Apenas um trabalho foi encontrado na literatu$\mathrm{ra}^{23}$, correlacionando especificamente CD-34 e caspase-3. Neste estudo conseguiu-se demonstrar que ao se estimular, em cultura, a proliferação de células CD-34 positivas de medula óssea, observava-se somente caspase-3 inativa no sistema. No entanto, 12 horas após a supressão do estímulo angiogênico, observou-se a clivagem ou ativação da caspase-3 com conseqüente apoptose das células CD-34 positivas. Ficou demonstrado assim a clara relação entre a supressão da angiogênese e o aumento da apoptose. Isto foi descrito também na fase avascular (latente) da tumorigênese onde a apoptose encontra-se aumentada em até 3 vezes em relação à fase angiogênica tumoral ${ }^{23}$.

Em relação ao trabalho aqui apresentado, devido ao número amostral escasso, a análise dos resultados citofotométricos foi feita pelo cálculo das medianas dos índices de marcagem para se evitar erro estatístico que os valores discrepantes dos índices poderiam causar sobre o cálculo das médias. A maioria dos trabalhos na literatura, no entanto está baseada na análise das médias do índice de marcagem ou da densidade microvascular.

Algumas variáveis como sexo e grau histológico não puderam ser avaliadas estatisticamente devido ao baixo número amostral de alguns dos grupos.
Observou-se discreta tendência à correlação positiva entre o índice de marcagem do CD-34, a invasão tumoral (T2 e T3) e acometimento linfonodal (NO e N1), com $P$ de 0,11 e 0,12 respectivamente. Esta correlação foi melhor demonstrada por outros trabalhos ${ }^{4,24}$ com $P<0,05$. Não houve correlação entre o marcador da caspase-3 com nenhuma das variáveis estudadas, em discordância com a literatura ${ }^{19}$ que relata correlação positiva com todas as mesmas variáveis, exceto idade.

O índice de marcagem do CD-34 apresentou valor de mediana significativamente inferior ao da caspase-3 $(P=0,007)$, inferindo melhor expressividade do marcador anti-caspase-3 no tumor em questão. Isso já era esperado uma vez que o CD-34 marca uma glicoproteína transmembrana ao passo que a caspase-3 marca uma proteína citoplasmática, portanto com mais área de ação.

Diferente de diversos estudos com outros marcadores de angiogênese e apoptose descritos na literatura, neste estudo não se observou correlação significativa entre os marcadores CD-34 e caspase-3. Houve, no entanto, discreta tendência positiva entre estes marcadores, contrária a diversos trabalhos que demonstram correlação negativa entre a angiogênese e a apoptose. Este resultado discrepante pode ser explicado pelo próprio marcador de apoptose utilizado que foi a caspase-3 não-clivada (32KDa). Este marcador, por não ser funcionalmente ativo, pode não refletir o fenômeno apoptótico real. Marcadores como a caspase-3 clivada (20KDa) e o método de TUNEL (transferase dUTP digoxigenin Nick and label), utilizados nos trabalhos referenciados, por terem maior sensibilidade ao fenômeno de apoptose, podem explicar os resultados conflitantes em relação a estes.

Fazem-se necessárias novas e mais amplas investigações com maior casuística e marcadores mais sensíveis à apoptose, como por exemplo a caspase-3 clivada, para melhor se compreender a correlação entre angiogênese e apoptose tumoral no carcinoma epidermóide de esôfago. A análise citofotométrica computadorizada vem se firmando como método de leitura ideal para os estudos imunoistoquímicos, pois permite maior rapidez de análise, menor subjetividade na quantificação da expressão dos marcadores e melhor tratamento estatístico dos dados encontrados. Tais entendimentos podem abrir novas perspectivas na avaliação de prognóstico, definir protocolos de tratamento e acompanhamento terapêutico.

Em conclusão, ambos os marcadores têm boa expressão no carcinoma epidermóide de esôfago, onde o CD-34 tem menor expressividade que a caspase-3 e os mesmos não apresentam correlação entre si. 


\section{A}

Objectives: To analyze by cytophotometry study the expression of CD-34 angiogenesis and caspase-3 apoptosis markers in the esophagus squamous cell carcinoma and to correlate markers themselves. Methods: Twenty-nine esophageal squamous cell carcinoma specimens were submitted to immunohystochemical analysis, based on label index of CD-34 and caspase-3 antibodies, using cytophotometry computer system. Variables considered in the correlation analysis were biomarkers expression quantification, patient age, lesion size, and TNM classification system. Results: Index label median value for CD-34 was 72,6\% and for caspase3 represented $96,5 \%$. Statistical significant correlation was not demonstrated between the respective biomarkers and lesion size $(p=0,96)$ or patient age $(p=0,95)$. There was a slightly tendency to a positive correlation between CD-34 index label and TNM classification system $(p=0,11)$. Although presenting a higher index label than CD-34 marker $(p=0,007)$, caspase-3 did not show any relationship with the studied variables $(p>0,19)$. The correlation between $C D-34$ and caspase-3 presented a small positive tendency $(r=0,09$ and $p=0,65)$. Conclusion: Both studied biomarkers showed good expression in esophageal squamous cell carcinoma, whereas CD-34 marker presented lower expression than caspase-3 in this specific tumor. The respective biomarkers do not demonstrate any correlation between themselves.

Key words: Antígenos CD34. Cytophotometry. Carcinoma, squamous cell. Esophageal neoplasms.

\section{REFERENCIAS}

1. Koshy M, Esiashvilli N, Landry JC, Thomas CR Jr, Matthews RH. Multiple management modalities in esophageal cancer: epidemiology, presentation and progression, work-up, and surgical approaches. Oncologist. 2004; 9(2):137-46.

2. Folkman J. Clinical application of research on angiogenesis. Sem Med Beth Hosp. 1995; 333(26):1557-63

3. Weidner N, Semple JP, Welch WR, Folkman J. Tumor angiogenesis and metastasis-correlation in invasive breast carcinoma. N Engl J Med. 1991; 324(1):1-8

4. Kitadai Y, Haruma K, Tokutomi T, Tanaka S, Sumii K, Carvalho M Kuwabara M, Yoshida K, Hirai T, Kajiyama G, Tahara E. Significance of vessel count and vascular endothelial growth factor in human esophageal carcinomas. Clin Cancer Res. 1998; 4(9):2195-200.

5. Igarashi M, Dhar DK, Kubota H, Yamamoto A, El-Assal O, Nagasue $\mathrm{N}$. The prognostic significance of microvessel density and thymidine phosphorylase expression in squamous cell carcinoma of the esophagus. Cancer. 1998; 82(7):1225-32

6. Kerr JF, Wyllie AH, Currie AR. Apoptosis: a basic biological phenomenon with wide-ranging implications in tissue kinetics. $\mathrm{Br} J$ Cancer. 1972; 26(4):239-57.

7. Thatte U, Bagadey S, Dahanukar S. Modulation of programmed cell death by medicinal plants. Cell Mol Biol. 2000; 46(1):199-214

8. Folkman J. Angiogenesis and apoptosis. Semin Cancer Biol. 2003; 13(2):159-67.

9. Beliën JA, Somi S, de Jong JS, van Diest PJ, Baak JP. Fully automated microvessel counting and hot spot selection by image processing of whole tumour sections in invasive breast cancer. J Clin Pathol. 1999: 52(3):184-92.

10. Mary J, Rigaut J, editors. Quantitative image analysis in cancer cytology and histology. Amsterdam: Elsevier Science Publishers; 1986.

11. Risau W, Flamme I. Vasculogenesis. Annu Rev Cell Dev Biol. 1995 . 11:73-91.

12. Folkman J, D'Amore PA. Blood vessel formation: what is its molecular basis? Cell. 1996; 87(7):1153-5.

13. Nicosia RF, Tchao R, Leighton J. Angiogenesis-dependent tumor spread in reinforced fibrin clot culture. Cancer Res. 1983 43(5):2159-66

14. Katz FE, Tindle R, Sutherland DR, Greaves MF. Identification of a membrane glycoprotein associated with haemopoietic progenitor cells. Leuk Res. 1985; 9(2):191-8.

15. Asahara T, Murohara T, Sullivan A, Silver M, van der Zee R, Li T, Witzenbichler B, Schatteman G, Isner JM. Isolation of putative progenitor endothelial cells for angiogenesis. Science. 1997; 275(5302):964-6

16. Asahara T, Masuda H, Takahashi T, Kalka C, Pastore C, Silver M Kearne M, Magner M, Isner JM. Bone marrow origin of endothelial progenitor cells responsible for postnatal vasculogenesis in physiological and pathological neovascularization. Circ Res. 1999; 85(3):221-8.

17. Fesik SW, Shi Y. Structural biology. Controlling the caspases Science. 2001: 294(5546):1477-8.

18. Hsia JY, Chen CY, Chen JT, Hsu CP, Shai SE, Yang SS, Chuang CY, Wang PY, Miaw J. Prognostic significance of caspase-3 expression in primary resected esophageal squamous cell carcinoma. Eur J Surg Oncol. 2003; 29(1):44-8.

19. Cao FM, Zhang $X H$, Yan $X$, Wang JL, Xing LX, Wang $X L$, Shen $H T$, Wang FR. [Expression and prognostic significance of survivin and caspase-3 in esophageal squamous-cell carcinoma and their relationship with HSPs expression]. Zhonghua Zhong Liu Za Zhi. 2005; 27(7):416-9.

20. Fitzgibbons $P L$, Page $D L$, Weaver $D$, Thor $A D$, Allred DC, Clark GM, Ruby SG, O'Malley F, Simpson JF, Connolly JL, Hayes DF, Edge SB, Lichter A, Schnitt SJ. Prognostic factors in breast cancer. College of American Pathologists Consensus Statement 1999. Arch Pathol Lab Med. 2000; 124(7):966-78

21. Vermeulen PB, Gasparini G, Fox SB, Colpaert C, Marson LP, Gion M, Beliën JA, de Waal RM, Van Marck E, Magnani E, Weidner $N$, Harris $A L$, Dirix LY. Second international consensus on the methodology and criteria of evaluation of angiogenesis quantification in solid human tumours. Eur J Cancer. 2002; 38(12):1564-79

22. Fox SB, Leek RD, Weekes MP, Whitehouse RM, Gatter KC, Harris AL. Quantitation and prognostic value of breast cancer angiogenesis: comparison of microvessel density, Chalkley count, and computer image analysis. J Pathol. 1995; 177(3):275-83.

23. Holmgren L, O'Reilly MS, Folkman J. Dormancy of micrometastases: balanced proliferation and apoptosis in the presence of angiogenesis suppression. Nat Med. 1995; 1(2):149-53.

24. Tanigawa $N$, Matsumura $M$, Amaya $H$, Kitaoka A, Shimomatsuya T, Lu C, Muraoka R, Tanaka T. Tumor vascularity correlates with the prognosis of patients with esophageal squamous cell carcinoma. Cancer. 1997; 79(2):220-5

Recebido em 27/08/2008

Aceito para publicação em 27/10/2008

Conflito de interesse: nenhum

Fonte de financiamento: nenhuma

\section{Como citar este artigo}

Ferreira VA, Czeczko NG, Ribas-Filho JM, Malafaia O, Ribas CA, Gomes CS, Cunha RM. Expressão dos marcadores tumorais CD-34 e caspase3 no carcinoma epidermóide de esôfago. Rev Col Bras Cir. [periódico na Internet] 2009; 36(1). Disponível em URL: http://www.scielo.br/rcbc

\section{Endereço para correspondência:}

Valério Alves Ferreira

E-mail: ipem@evangelico.org.br 